\title{
Issues in Implementing CRM: A Case Study
}

\author{
Rui Da Silva and Ilan Rahimi \\ Manchester Business School, England, UK
}

\author{
rvdasilva@man.mbs.ac.uk irahimi@man.mbs.ac.uk
}

\begin{abstract}
In recent years several large organizations in Israel implemented CRM systems in order to increase efficiency. The difficulties managers and decision makers in all fields of business have to face are great as there is no one 'fixed formula' to guarantee the success of such a maneuver. However, there is a set of guidelines that can assure the road to success of such a change when one wishes to implement an ERP system.

Holland and Light's (1999) CSF model that was designed to ensure successful ERP implementation is at the heart of the present paper. They present tactical and strategic processes to ease such a process. This paper shall focus on two of the following issues: First the paper will examine whether it is possible to extend the Holland and Light model and make it suitable to CRM implementation, and second, it will review the modifications that the model must undergo in order to achieve this objective.

Twenty companies of various industrial fields that implemented CRM were reviewed. The paper presents the case study of three of these companies. The analysis of the interviews and survey that is currently being processed in Israel will be presented at the conference.
\end{abstract}

Keywords: ERP, CRM Implementation, CSF, Management, Customer, Relationship.

\section{Introduction}

The use of CRM (Customer Relationship Management) systems in diverse industries is now common around the globe. However, the fact that many companies have undergone this process does not mean that it's easy to implement such a system, let alone decide to go through such a process. In fact, because of the substantial investment needed, many expect a return on this investment. In reality most of the time that expectation is not fulfilled. Usually $50 \%-70 \%$ of the times the project fails (Morrel \& Philonenko, 2001).

The reason a CRM project fails lies in the way companies regard CRM systems. Light (2001) claims that because companies view CRM as a technological project that is bounded by time and budget instead of regarding CRM as a long term commitment to efficiency and improvement, the project will definitely fail. Ryals, Knox, and Maklan, (2001) agree with Light's view and contend that CRM should by regarded as a holistic view including a strategy that permits organizational changes and organizational processes. The technological should not be overlooked in the process

Material published as part of this journal, either on-line or in print, is copyrighted by Informing Science. Permission to make digital or paper copy of part or all of these works for personal or classroom use is granted without fee provided that the copies are not made or distributed for profit or commercial advantage AND that copies 1) bear this notice in full and 2) give the full citation on the first page. It is permissible to abstract these works so long as credit is given. To copy in all other cases or to republish or to post on a server or to redistribute to lists requires specific permission from the publisher at Publisher@InformingScience.org but one has to remember that is only means to an end.

Holland and Light (1999) present a model that includes Critical Success Factors to insure swift ERP implementation. It is based on tactical and strategic factors, and on Slevin and Pinto's (1987) model that was modi- 
fied by the two. It is argued in this paper that ERP and CRM implementation processes are similar. Therefore we aim to check two main issues: (a) Can Holland and Light's (1999) model for critical success factors be applied to CRM, and (b) What modifications in their model that reviewed ERP systems should be adapted to CRM implementation.

The case study of three companies reviewed for this paper is presented here. The review leads to the conclusion that Holland and Light's (1999) model can be extended to the implementation of CRM systems.

The next section presents key definitions concerning CRM and CSF. Following that is a review of the research methodology used; a review of the three case studies is next. Finally, we present an analysis that leads to the conclusion of the current paper.

\section{Customer Relationship Management Framework}

Despite the fact that CRM as a concept has emerged only recently in both the IT and marketing fields, the literature offers multiple definitions of CRM. Four definitions were chosen to demonstrate the correlation between Information Systems and Marketing, both of which comprise the two major components of CRM:

- $\quad$ "CRM is at the core of any customer-focused business strategy and includes the people, processes, and technology questions associated with marketing, sales, and service". (See http://www.realmarket.com/crmdefine.html)

- "CRM is defined as a management approach that enables organizations to identify, attract and increase retention of profitable customers by managing relationships with them" (Ryals et al., 2001).

- “..practicing elements of an approach to marketing that uses continuously refined information about current and potential customers to anticipate and respond to their needs" (Peppard, 2000).

- "CRM is not a technology or even a group of technologies. It is a continually evolving process that requires a shift in attitude away from the traditional business model of focusing internally. CRM is an approach a company takes toward its customers supported by thoughtful investment in people, technology and business processes" (Morrel \& Philonenko, 2001).

With regards to the Marketing component of CRM, Kutner and Cripps (1997) emphasize that CRM is all about the customer: Customers must be viewed as the company's most important. In addition, they claim that contrary to previous attitudes, customers are very different in their need, preferences and buying habits and are not equally desirable as each one generates different profits. Therefore, companies should draw customer profiles and follow their customers' drivers and profitability. In turn companies can maximize profits by offering customers goods according to their profile.

On the other hand, with regards to the Information Systems component, CRM has to be technologically characterized as follows:

- It should include a customer database including contracts, transactions and channel data.

- Tools for analysis should be available in order to examine the database and identify customer behavior patterns. 
- Management must provide tools that would enable the Marketing department to define communication channels, which in turn should be automatic and easy to use.

The interface with the operational environment would maintain the marketing database and communication channels to deliver the messages (Curley, 1999).

The origin of CRM is also linked to these two components. In the Information System arena CRM has evolved following developments in ERP in the last two decades. With ERP, organizations maximized operational efficiency (Light, 2001). It was believed that using these systems would increase efficiency and effectiveness; hence it would lead to customer satisfaction (Light, 2001). The later development of CRM proceeded from that point exactly: shifting focus on the customer and his environment instead of focusing on the product and manufacturing.

In the Marketing scene, CRM is not considered to be a new concept at all. Researchers claim that in actuality, organizations have been managing customer relationships for a while (Fletcher, 1999). The new element in this relationship is the use of software to facilitate this relationship.

The CRM approach dictates that the 4Ps (Product, Price, Place, Promotion) should be carefully considered by the organization. However, the functional needs should be integrated to meet customer satisfaction. The previous marketing approach focusing on customer acquisition is now replaced with the approach calling for customer retention (Christopher, Payne, \& Ballantyne, 1998).

Despite the fact that CRM may have been here for some time, well disguised under different names, the role of the Information System in establishing CRM as a concept is fundamental. CRM enables organizations to reach maximum profit by obtaining accurate information on targeted markets or market segments, using databases, data warehouse, data mining, one-to-one marketing, automated call centers and sales force automation. These features are made possible thanks to the advent of computerized systems that help organizations sort through the huge pieces of information they collect. It is assumed that the more organizations learn about the customer, the more they can offer the right goods and services to the suitable market, hence, increase sales and profit (Newell, 2000; Ryals et al., 2001).

\section{CRM Characteristics and Solutions}

Dean (2001) identifies three layers that characterize the complexity of CRM. The first layer is the operative one. Its objective is to manage all points of contact with the customer (service, sales and marketing). The collaborative CRM is the second layer. It offers customers a spectacular view of the organization and enables the customer to complete some tasks, to communicate with the organization, and to receive updated information through the different operational channels the organization offers. The third layer is the analytical CRM that contains technologies that analyze data received from interaction with the customer. The analysis is translated into future actions beneficial both to the customer and to the organization (Chang, 2001).

\section{Implementing ERP and CRM}

As previously noted, CRM is derived from ERM (Enterprise Resource Management, or Enterprise Resource Planning ERP, as it is most commonly known). ERP systems manage the organization's needs, while making it possible for managers to handle all of the organizational activities and tasks. ERP originated in logistics and manufacturing systems. The central elements of those systems allow management some in-company activities while at the same time the interface with the external world remains untouched. 
ERP is defined as follows:

- $\quad$ "ERP software automates core corporate activities, such as manufacturing, human resource, finance and supply chain management, by incorporating best practices to facilitate rapid decision-making, cost reductions, and greater managerial control" (p.31), (Holland \& Light, 1999).

- $\quad$ "From a business perspective the software and the business processes need to be aligned which involves a mixture of business process design and software configuration. The focus of ERP projects is therefore much more on BRP activities than more traditional systems development projects that still typically retain a high technical component", (p.1), (Gibson, Holland \& Light, 1999).

- $\quad$ "ERP has grown as an integration tool where the aim is to integrate all enterprise applications to a central data repository with easy and discrete access to all relevant parties" (p.275), (Black 1999, in Mandal \& Gunasekaran, 2003).

- $\quad$ ERP provides two major benefits that do not exist in non-integrated departmental systems: (1) a unified enterprise view of the business that encompasses all functions and departments, and (2) an enterprise database where all business transactions are entered, recorded, processed, monitored, and reported", (p.241), (Umble, Haft \& Umble, 2003).

The definitions of ERP emphasize the similarities and the differences between CRM and ERP systems. The most evident similarity is that the implementation process of both systems is executed from a strategic point of view, and is not a mere software implementation. The major difference lies in the fact that each system focuses on a different element. ERP focuses on internal processes and resource management (e.g. employees and finance, manufacturing certain products, etc.). On the other hand, the CRM approach focuses on the customer and to that end consists of marketing, selling, customer service and call center models.

Keen (2000) suggests that in order to ensure the success of a CRM system, one should review what happened in ERP ventures. More specifically he notes that "what went wrong or right with ERP will almost surely happen with CRM. Whatever was unanticipated or underestimated then will likely be the same today.... those who ignore history are condemned to repeat it."

\section{CSF - Critical Success Factor Model}

The Critical Success Factors (CSF) are defined as "those characteristics, conditions or variables that, when properly sustained, maintained, or managed, can have a significant impact on the success of a firm competing in a particular industry" (Leidecker \& Bruno, 1987). Because the CSF model has emerged from the management community, it is business oriented. The CSF model is used to identify and prioritize business needs and technical systems (Flynn \& Arce, 1997).

As such, Somers and Nelson (2001) claim that CSF should be viewed as "situated exemplars that help extend the boundaries of process improvement, and whose effect is much richer if viewed within the context of their importance in each stage of the implementation process".

Holland and Light's model (1999) is based on that of Slevin and Pinto (1987). Slevin and Pinto offered 10 success factors broken into tactical and strategic factors, for project implementation. 
Slevin and Pinto (1987) claim that both strategic and tactical factors are essential for successful project implementation only when these factors are viewed visà-vis the project's life cycle (i.e. Conceptualization, Planning, Execution and Termination). For example, strategic issues are crucial in the first stages but tactical issues gain importance toward the end.

Holland and Light's CSF model (1999) as shown in Table 1 is a customization of the Slevin and Pinto model (1987). Their customized model is broken into strategic and tactical factors as well, but these were modified so that each factor will be "specific to ERP projects" (Holland \& Light, 1999).

\section{Research Methodology}

The objective of this paper as outlined in the introduction is to examine whether Holland and Light's CSF model can be applied and extended (with some changes) to the implementation of CRM systems. The Case Study method is best suited to this examination, because, as CRM is basically a new phenomenon very little research has been carried out so far. Hence, it is very difficult, almost impossible, to measure it in quantitative terms. (Benshabat, Goldstein \& Mead, 1987, in Trauth, 2001).

The literature assigns five central characteristics to the Case Study method, of which the most crucial to this paper's objectives is thorough research. Thorough research provides an insightful observation into the phenomenon and all of its fine points (Denscombe, 1999). It allows one to conduct true "drilling" that best suits the required study and understandings of processes and new phenomena (Labovits \& Hagedron, 1981).

The companies reviewed for this paper are different in terms of their size, industry and the emphasis each company centers on in the CRM implementation and/or use. The diversity of these organizations is not accidental. The rationale behind this selection (see Table 2) is the need to view Holland and Light's principles in as wide a context as possible.

The questions asked in the semi-structured interviews are based on pre-research in which forty information system analysts, members of the information system analysts committee, were asked questions regarding CSFs in CRM systems.

Additional information on the companies, such as annual reports or company review, was obtained from various web sites.

Table 2 is a list of the companies reviewed for this research: 
Table 2: List of firms reviewed sectioned by industry and implementation role

\begin{tabular}{|c|c|c|}
\hline Company & Industry & Implementation Role \\
\hline Bezeq Ltd. & Communication & Using CRM \\
\hline Lines & Communication & Using CRM \\
\hline Banco Ltd. & Banking & Using CRM \\
\hline Fibers Co. & Textile & Using CRM \\
\hline Microsoft & System Software & Using and selling CRM solution \\
\hline Widelink & Consultation & CRM consulting firm \\
\hline Alternative & Consultation & $\begin{array}{l}\text { CRM consulting firm } \\
\text { Selling and implementing CRM so- } \\
\text { lutions }\end{array}$ \\
\hline Seker Consult & Consultation & CRM consulting firm \\
\hline Bezeq Online & Communication & Using CRM \\
\hline Oracle & System Software & Selling and implementing CRM \\
\hline Netvision & Internet & $\begin{array}{l}\text { Selling and implementing CRM } \\
\text { Using CRM }\end{array}$ \\
\hline Banco Na. & Banking & Using CRM \\
\hline Tau & Consultation & CRM consulting firm \\
\hline Dubek & Manufacturing - Industrial & Using CRM \\
\hline Opisoft & System Software & Selling and implementing CRM \\
\hline Yael Software & System Software & Selling and implementing CRM \\
\hline Sinergy & System Software & Selling and implementing CRM \\
\hline New Applications & System Software & Selling and implementing CRM \\
\hline $\begin{array}{l}\text { Deloitte Brightman } \\
\text { Almagor }\end{array}$ & Consultation & CRM consulting firm \\
\hline Tami & Consultation & CRM consulting firm \\
\hline
\end{tabular}

Out of the list in Table 2, key people from these 20 companies were interviewed during a period of 18 months. Some of names (company names) were altered to protect the firms, yet case details are accurate.

Full review of three out of the twenty companies listed in table 2 is presented. The review contains enough theoretical content to support the arguments this paper wishes to sustain. The case studies of Fibers Co., Bezeq Ltd., and Banco Ltd. are presented: 


\section{Case Data}

\section{Fibers Co.}

Fibers Co. is a prestigious international firm that manufactures nylon yarns for the garment and textile industry. It's yarn solutions allow fabric manufacturers to create comfortable hosiery, lingerie and active wear. The firm is committed to manufacturing high quality goods. It operates in Israel, the United States, and in several European countries, such as Italy, the United Kingdom and France. It should be noted that more than $90 \%$ percent of its goods are exported, which definitely indicates it's dependence upon other business factors from abroad. It's annual sales amount to more than a hundred million dollars per year.

A SAP operational ERP system was implemented in 1998. The SAP system constitutes the foundation of the firm's information system. The system supports the manufacturing process, and the sales and marketing of Fibers Co. goods in Israel and abroad. The computerized system operates in an open system environment.

The firm's business activity is based on a small number of multi-year business transactions. The scope of those transactions is wide.

The managers asserted that a CRM system should be implemented because of the firm's B2B business nature. They believed that based on the nature of the transactions the company handles, the value of each customer and each supplier is tremendous. Lack of a CRM system would harm the company's chances to retain ongoing projects and to develop new ones in the future. Only a CRM system would allow the company to view its clients as true assets.

In addition, it should be emphasized that the sold goods are not uniform over-the-counter goods, but rather goods that are tailored to each client's needs, and therefore, the needs of each client, many of them manufacturers themselves, should be regarded as a project. Each client has different needs and demands customization of Fibers Co. goods. Each project affects the profitability. (The needs are characterized by the R \& D teams of both the clients and Fibers Co.)

As for the reasons leading to successful implementation of CRM, managers at Fibers Co. emphasized that the project succeeded due to the organization's ability to implement the CRM philosophy among its employees. Only this kind of implementation guaranteed maximal use of the CRM capabilities. As for the link to existing operational systems, the choice of mySAP CRM was natural, based on the assessment that such linkage was crucial to the success of the CRM project.

The project was executed in several stages, following the project plan step by step. It used the end users' mother tongue during the input data stage (in complete opposition to the supposition that the used language has to be the same throughout the implementation process). These two implementation features were chosen to assure a system that is easy to use and has high client acceptance. The gradual implementation was limited to one department at a time. This way the company could perform a structured process of monitoring and feedback, allowing the organization to avoid technological complications and control schedule and budget.

Throughout the project, managers emphasized their commitment to the CRM implementation process. Without an active commitment, there is a slim chance such a project would succeed.

\section{Banco Ltd.}

Banco is a bank that heads a group of banks rated fifth place in Israel. The quick growth enjoyed by the bank in recent years has immensely increased the bank's profit, income and activity. Among the bank's activities are financial services such as credit and loans, trust funds, foreign 
currency, international commerce, mortgage, savings and leasing. The bank's activities are carried out in its Israeli branches, in London, and in Zurich.

The bank's clients are large business corporations and private investors. It is a leader in three fields: capital market and foreign currency, private banking and business banking. The bank offers a wide range of unique direct banking services (e-banking) that allows it to reach a large number of customers using new innovative initiatives that suit their financial needs. This customization of solutions to meet customer needs led to the need to review a CRM system.

In light of the competition in the market with other banks, Banco has upgraded its traditional field of private banking activity in the past year. The bank set a goal to increase its market share of business customers defined as Middle Market. To that end, some thirty branches specializing in private banking were drafted. These specialized branches emphasized the bank's vision that the customer is at the heart of its activities. Simultaneously, the bank penetrated the retail sector by defining specialized branches and developing new goods and machines to better serve this sector.

At the same time, the bank outlined a CRM draft that would serve all branches in providing information to the customer and performing banking activities via the phone and the Internet. This step was declared a success on both the technological managerial levels as service improved.

Since the project was viewed as key bank strategy, the bank appointed top bank officials for the implementation stage of the project and the management of CRM afterwards.

The project was complex. First, IP Call Center technology was used for the first time in Israel. Second, the implementation of the project demanded cooperation between several large corporations, each specializing in its field (such as CRM software solutions, active communication hardware, infrastructure, etc.) to connect to the bank's already existing information systems.

Those involved in the project noted that it was headed for success because of the integrator's professionalism, the bank's demand to stick to the project schedule, the bank's commitment to the CRM project, and, mainly, because the bank regarded the project as a strategic rather than a technological project.

Banco's CRM project was declared as the best CRM project in a competition held in 2003. The competition took place under the auspices of the leading magazine Information Week and the People and Computers Group. Today the Call Center handles 40,000 calls a month.

\section{Bezeq Ltd.}

Bezeq is the communication monopoly in Israel previously operated by the Israeli Postal Ministry that, since the early seventies controlled the telephony business. Bezeq is still the only supplier permitted to install phone lines and is involved in other related fields, such as the cellular market and international calls. It operates as one of the leading ISPs (Internet Service Provider) in Israel in terms of content and internet and is involved with cable TV.

Changes in the communication arena i.e. growing competition among the cellular companies, high pressure by customers to lower prices, and the increasing use of Voice Over IP products, led Bezeq to review a new marketing and organizational approach. The company aimed at changing its reputation from an operational oriented company to a customer oriented company dedicated to high quality service.

The adaptation of CRM resulted in major changes: on the macro level, a separation of the business and private call centers and adaptation to ISO 2002 standards; on the micro level, the rate structure was simplified and the monthly phone bill was given a new, innovative look. 
Other measures taken by Bezeq include segregation of service based on private and business customers, improvement of service, introduction of new services and products and, mainly, an attempt to change the company's notorious reputation in the Israeli market.

Prior to implementation of CRM, Bezeq worked with several widely dispersed information systems, which did not permit an overall view of the customer. Few management and supervision tools existed. Moreover, Bezeq used passive operational channels with its customers: the customer was taken care of only when he turned to Bezeq.

After implementing CRM Bezeq became a company that works with a single information system, and greatly improved its reputation among customers. Instead of a company that works with several information systems whereby the information on the customer is widely dispersed. This kind of situation did not permit an overall look on the customer especially when no management and supervision tools existed and, on top of it all, Bezeq used passive operational channels with its customer: the customer was taken care of only when he turned to Bezeq. However, that status changed completely. .Bezeq is now using active operational channels; it collects relevant customer data, learns about customer communication usage and occasionally offers customers new goods and services.

The understanding that CRM is not merely a computerized system, but a management philosophy that has to be implemented in all levels of the organization, is the main reason for the success of the CRM project. Another factor that contributed to this success, as mentioned by some of the interviewees, is the full commitment of management to the process. This commitment was eminent not only in the service policy the company rephrased and disseminated among it employees and customer, but mainly in resource allocation of personnel and financing.

On the technological level, the interviewed managers mentioned the unification and link between the systems and the establishment of information systems such as a new Billing system for the business sector, a sophisticated routing to the 199 centers (CTI system) and the foundation of a reliable Data Warehouse. These factors also influenced the success of the CRM.

The company operates ERP systems that handle company resources such as the billing system that produces invoices based on 30 million data units per day, totaling billions of data units per month. More than a million and a half bills are sent out to customers every month.

The Call Center operates 24 hours a day and handles $98 \%$ of all calls received on any given day. The web-based service is still problematic because of security and privacy issues. Even so, this operational channel is under constant development and improvement.

\section{Case Discussion and Conclusions}

The research scanned companies of diverse industries that had undergone the CRM process in order to view the CSFs Holland and Light defined as relevant to the process and in order to check what necessary changes must take place in order to adopt the CSF to the implementation process.

The case studies reviewed here show that the criteria viewed by project participants as critical for successful CRM implementation are very similar.

The initial research results indicated that the technological factor was marginal in terms of its contribution to the success of the CRM project. Other factors found to be much more crucial are:

- Full understanding of the company's organizational and marketing philosophy whereby the customer is as the heart of the organizational goals 
- Adequate characterization of the implementation objectives at the planning stage of the CRM project.

- Top management involvement throughout the various stages of the project.

- Acknowledgment that the CRM implementation process has a long-term affect on the organization.

- Understanding that the CRM system has to be linked to other information systems.

- A professional team that understands the technology involved and is familiar with the organizational process.

Following these modifications, Holland and Light's (1999) CSF model should be revised as follows:

Table 3: Revised essential strategic and tactical CSFs for CRM implementation

\section{\begin{tabular}{l|l} 
Strategic CSF & Tactical CSF
\end{tabular}}

CRM philosophy

Project mission

Top management commitment

Project schedule and plans
Client consultation

Connectivity

Skillful personnel

Technical tasks

Client acceptance

Monitoring and feedback

Communication

Troubleshooting

BPS and software configuration

The reviewed cases in this paper and other cases as well, lead to the conclusion that there is a tight link between the guidelines used in implementing ERP systems and the guidelines used in implementing CRM systems. However, Holland and Light's (1999) CSF model must change in order to suit implementation of CRM systems.

Among the strategic CSFs, the CRM philosophy should be noted, whereas changes such as connectivity and technical tasks can be listed among the tactical CSF changes.

The research method of Case Study analysis is limited in the sense that it is somewhat difficult to generalize from the observed cases to the issue at hand. Moreover, it is hard to build a theory based on the instances reviewed. (Denscombe, 1999; Labovits, \& Hagedron, 1981) Therefore, more cases must be reviewed.

Still, a qualitative research of a wider magnitude would allow confirming the link between the ERP and CRM implementation processes. 


\section{References}

Buttle, F. (1996). Relationship marketing: Theory and practice ( $1^{\text {st }}$ ed.). London: Paul Chapman Publishing.

Chang, J. (2001). CRM Suits for Medium to Large Enterprises. The CRM Solution Guide. Retrieved from www.CRMguru.com

Christopher, M., Payne, A., \& Ballantyne, D. (1998). Relationship Marketing: Bringing Quality, Customer Service, and Marketing Together. Oxford: Butterworth Heinemann.

Curley, B. (1999). Profiting from the relationship. Insurance and Technology, 24 (3), 34-38.

Dean, J. (2001). Better business through customers. Government Executive, 33 (1), 58.

Denscombe, M. (1999). The good research guide: For small-scale social research projects. London: Open University Press.

Dun and Bradstreet Israel. (2002). DB Israel Guide.

Eisenhardt, K. M. (1989). Building theories from case study research. Academy of Management Review, 14 (4), 532-550.

Fletcher, K. (1999, March 11). Data focus on customers. Marketing, pp. 52-53.

Flynn, D. J. \& Arce, E. A. (1997). A Case tool to support critical success factors analysis in IT planning and requirements determination. Information and Software Technology, 39, 311-321.

Gibson, N., Holland, C. \& Light, B. (1999). Enterprise resource planning: A business approach to systems development. The 32nd Hawaii International Conference on System Sciences, IEE, 1-9.

Holland, C. \& Light, B. (1999). Critical success factors model for ERP implementation. IEEE Software, May/June.

Jones, D. (2000). Customer relationship management. London: Caspian Publishing.

Keen, P. G. W. (2000). ECRM: The new ERP. Computerworld, 34 (28).

Kutner, S. \& Cripps, J. (1997). Managing the customer portfolio of healthcare enterprises. The Healthcare Forum Journal, 40 (5), 52-54.

Labovits, S. \& Hagedron, R. (1981). Introduction to social research. New York: McGraw Hill.

Leidecker, J. K. \& Bruno, A. V. (1987). CSF analysis and the strategy development process. In Strategic planning and management handbook (pp. 333-351), Van Nostrand Rheinhold.

Light, B. (2001). A review of the issues associated with customer relationship management systems. The 9th European Conference on Information Systems, June 2001.

Mandal, P. \& Gunasekaran, A. (2003). Issues in implementing ERP: A case study. European Journal of Operational Research, 146, 274-283.

Morrel, S. \& Philonenko, L. (2001). 20:20 CRM: A visionary insight into unique customer contact. San Francisco: Genesys Telecommunications Laboratories.

Newell, F. (2000). Loyalty.com: Customer relationship management in the new era of Internet marketing. New York: McGraw-Hill.

Peppard, J. (2000). Customer relationship management (CRM) in financial services. European Management Journal, 18 (3), 312-327.

Rockart, J. F. (1979, March-April). Chief executives define their own data needs. Harvard Business Review, 81-93.

Ryals, L., Knox, S., \& Maklan, S. (2001). Customer relationship management (CRM): Building the business case. Edinburgh: Pearson Education. 
Slevin, D. P \& Pinto, J. K. (1987). Balancing strategy and tactics in project implementation. Sloan Management Review, 29, 33-41.

Somers, T. M. \& Nelson, K. (2001). The impact of critical success factors across the stages of enterprise resource planning implementations. Proceedings of the $34^{\text {th }}$ Hawaii International Conference on System Sciences - 2001.

Stake, E. R. (1995). The art of case study research. London: Sage Publications.

Trauth, E. M. (2001). Qualitative Research in IS: Issues and Trends. Idea Group Publishing.

Umble, E. J., Haft, R. R. \& Umble, M. M. (2003). Enterprise resource planning: Implementation procedures and critical success factors. European Journal of Operational Research, 146, 241-257.

Upton, M. (2001, July 12). CRM now, integration later. e-Business Trends. 65. www.idc.com

Yin, K. R. (1994). Case study research: Design and methods. London: Sage Publications.

\section{Biographies}

Dr. Rui Da Silva is a Lecturer in Marketing at the University of Manchester Business School, in Manchester, England. In this capacity he teaches the MBA programme at MBS and supervises $\mathrm{PhD}$ students. He is also a guest lecturer at the University of Sao Paulo. His undergraduate degrees are in Business Administration and Economics. He also holds MBA and PhD degrees and conducted Post-Doctoral work prior to becoming a lecturer at MBS. His research interests are in the area of corporate reputation and industrial marketing.

Ilan Rahimi is a doctoral student at the University of Manchester Business School, in Manchester, England. He is the head of the Department of Information Systems Analysis department OAC - Ono Academic Colleges and teaches BA and MBA courses. He holds an MBA degree in Marketing from the University of Manchester and a BA degree in Information Systems from the College of Management, Israel. His current area of research is CSF in CRM and ERP implementations. 